\title{
Sensory Processing Disorder in Normally Developing Egyptian Children
}

\author{
Original \\ Article \\ Dina Khaled ${ }^{l,}$ Nirvana Gamal El Din Hafez ${ }^{2}$ \\ ${ }^{I}$ Lecturer of Phoniatrics, Department of Medical Studies, Faculty of Postgraduate Childhood \\ Studies, ${ }^{2}$ Professor of Phoniatrics, Faculty of Medicine, , Ain Shams University, Cairo, Egypt
}

\begin{abstract}
Objective: The aim of this study was to assess the sensory processing among typically developing children between 3-8 years old to follow any negative impact on their social and behavioral development.

Patients and Methods: Sensory processing abilities were assessed for 190 typically developing children by using the Short Sensory Profile (SSP)caregiver questionnaire. A typical sensory performance was defined as an SSP total score of: 190-155 and the total scores of typical sensory performances for tactile sensitivity:35-30; taste/smell sensitivity:20-15; movement sensitivity: 15-13; under-responsive/seeks sensation:35-27; auditory filtering:30-23; low energy/weak:30-26; and visual/auditory sensitivity: 25-19. Below these scores shows atypical sensory performance.

Results: The typically developed children showed some degree of sensory processing disorderon Under-responsive/ seek sensitivity as well as Taste and smell sensitivity. Some children in this study $(50.5 \%)$ showed a degree of sensory processing impairment in the SSP total score. An increase in the tactile sensitivity was significantly associated with higher prevalence of the movement sensitivity $(\mathrm{r}=0.745, p$ value $=<0.001)$. As for the Pearson correlation between the low energy/weak and the visual/auditory sensitivity is about $r=0.698$, which indicates that there is a moderate positive relationship between the 2 variables.

Conclusion: These findings showed the types of sensory processing disorder in typically developing children and the difference between female and male children. Future studies are required on larger samples to clarify more the types of sensory impairment in typically developing children and to confirm these results.
\end{abstract}

Key Words: Sensory integration, sensory processing disorder, short sensory profile (SSP).

Received: 09 August 2021, Accepted: 27 September 2021

Corresponding Author: Dina Mohamed Fouad, Department of Medical Studies, Faculty of Postgraduate Childhood Studies, Ain Shams University, Cairo, Egypt, Tel.: 002-22917445, E-mail: dinaakhaled@chi.asu.edu.eg

ISSN: 2090-0740, 2021

\section{INTRODUCTION}

Sensory processing is a general term that means how our neural systems handle any sensory information, which includes the role of the peripheral, central nervous systems and the receptor organs. According to Dunn, sensory processing is a difficult process. Sensory input from the environment and from the body provides information to the brain ${ }^{[1]}$. The processing of an information permits the comfortable, efficient automatic response of an individual to any received sensory inputs ${ }^{[2,3]}$.

Ayres focused on the relationship between sensory input, motor responses, and normal sensorimotor development. She defined sensory processing as the ability to organize sensory information to make adaptive responses ${ }^{[4]}$. Having a child with some sensory problems does not mean that he or she has sensory processing disorder. Many children may suffer hypersensitivity to specific types of stimuli such as loud noise or walking on sand bare footed. Few of them may be annoyed or perturbed in their life from these sensations. These children will be considered as children who have sensory processing disorder ${ }^{[5,6]}$. Any Behaviors relatedto sensory processing are not detected as abnormalities; these are differences, usually abilities, such as enhanced perception ${ }^{[7]}$.

Sensory processing or in other words Sensory integration (SI) is the behavioral \& motor response resulting from a certain sense received by the nervous system ${ }^{[8]}$. The degree of this response relies mainly on the sensory thresholds whether it is high or low which differs from one child to another ${ }^{[9]}$. Sensory processing refers to how the brain record and processes and operate sensory input 
from different sensory systems, including the five main senses as well as proprioception and vestibular senses ${ }^{[10]}$. The behavioral and motoric response based on the sensory processing of the child affects his/her quality of life \& his/ her daily life activities. Sensory processing is an active process all through the child development and is influenced by the environmental interaction, receiving different stimuli from the environment or the body ${ }^{[11]}$. Sensory registration problem which is one of the components of the sensory processing disorder is the failure in producing appropriate adaptive behavior against taste, touch, pain, sound, light, smell, and movement. As well as the hypo /hyperresponsiveness, hypersensitivity and sensory avoiding are symptoms for sensory modulation disorders which is another component of the sensory processing disorders. Sensory discrimination is one of the important components which is important for postural adjustment, tonus and motoric function development ${ }^{[12]}$.

Hypersensitive persons are characterized by having a low neurological threshold and easily notice sensory input, meaning that they are usually distracted by movement, sounds, textures, or smells not perceived by others ${ }^{[13]}$. In contrast, hyposensitive persons present low registration; they do not notice daily sensory events. For example, they may not notice when someone comes into a room or when they have food or dirt on their face and hands ${ }^{[14]}$.

\section{AIM OF THE STUDY}

The aim of this study was to detect any sensory processing disorder in typically (normally) developing children aged 3-8-year-old in order to follow any negative impact on their social and behavioral development.

\section{PATIENTS AND METHODS}

This study included 190 normally developing children aged between 3-8 years including 86 females (45.3\%) and $104(54.7 \%)$ males who their milestones were typically developing and did not suffer from any medical disorders and are not on any long-term medications. They were selected by simple random sampling. The variable in this study was determining how child process sensory information during his daily situations by using the Short Sensory Profile (SSP) questionnaire ${ }^{[15]}$. The Short Sensory Profile questionnaire is made up of 38 points. It is a caregiver questionnaire that measure the children's' responses to daily sensory events (SP; $\left.{ }^{[9]}\right)$. Each item is scored on a 1-to 5-point scale (Likert scale). The Short Sensory Profile caregiver questionnaire consists of seven sections which are the Tactile Sensitivity, Taste/Smell Sensitivity, Movement Sensitivity, Under responsive/ Seeks Sensation, Auditory Filtering, LowEnergy/Weak, and Visual/Auditory Sensitivity.The test lasted from 10-15 minutes for each child.

Short Sensory Profile questionnaire was provided to the mother/caregiver of each child and fulfilled by her. All the points were answered by the mother/caregiver. The idea of the questionnaire and how to choose the answers were explained to the mother then each question was asked to the mum in English orally as mentioned exactly in the SSP. Each item has from 3 to 7 assessing questions. The responses were measured by the following key; Always, Frequently, Occasionally, Seldom and Never.

'Always' was chosen when your child always responds in this manner ( $100 \%$ of the time). 'Frequently' was when presented with the opportunity, that $75 \%$ of the time your child frequently responds in this manner. 'Occasionally', was $50 \%$ of the time your child responds in this manner. 'Seldom' when presented with the opportunity, your child always responds in this manner, $25 \%$ of the time. Lastly, 'Never' when presented with the opportunity, your child always responds in this manner, $0 \%$ of the time.

\section{Data Collection}

The collected data was revised, coded, tabulated and introduced to a personal computer using Statistical package for Social Science (SPSS 20). Data was presented and suitable analysis was done according to the type of data obtained for each parameter. Descriptive statistics were used: Mean, Standard deviation $( \pm S D)$ and range for numerical data. Then, Frequency and percentage of nonnumerical data.Analytical statistics were used: Student $T$ Test was used to assess the statistical significance of the difference between two study group means. While ChiSquare test was used to examine the relationship between two qualitative variables. As well as Correlation analysis (using Pearson's and Spearman's method): To assess the strength of association between two quantitative variables. The correlation coefficient denoted symbolically "r and rs" defines the strength (magnitude) and direction (positive or negative) of the linear relationship between two variables.

- $\mathrm{r}=0-0.19$ is regarded as very weak correlation

- $\mathrm{r}=0.2-0.39$ as weak correlation

- $\mathrm{r}=0.40-0.59$ as moderate correlation

$\bullet r=0.6-0.79$ as strong correlation

- $\mathrm{r}=0.8-1$ as very strong correlation

\section{RESULTS}

\section{Descriptive statistics:}

\section{Sensory processing abilities on the SSP}

Table 1 shows the mean SD and the range among all age groups for the 7 items of the SSP including Tactile Sensitivity, Taste/Smell Sensitivity, Movement Sensitivity, Underresponsive/Seeks Sensation, Auditory Filtering, LowEnergy/Weak, and Visual/Auditory Sensitivity.There were significant results in the tactile sensitivity and low energy/weak among the other items of the SSP. 
Table 2 shows the number and the percentage of each result among all age groups for the 7 items. The Underresponsive. seek sensitivity showed the highest percentage in the 'definite difference' result while visual/auditory sensitivity and low energy / weak showed the highest percentage in the 'typical performance' result, as well as the visual/auditory sensitivity showed the highest percentage in the "probable difference' result in comparison to the other items of the SSP.

Table 1: The performance reported on the SSP for all age groups.

\begin{tabular}{lcc}
\hline & Mean \pm SD & Range \\
\hline Age & $5.36 \pm 1.78$ & $3-8$ \\
Tactile sensitivity & $27.37 \pm 5.51$ & $14-35$ \\
Taste and smell sensitivity & $12.78 \pm 4.75$ & $4-20$ \\
Movement sensitivity & $11.48 \pm 3.02$ & $5-15$ \\
Underresponsive.seek sensitivity & $23.38 \pm 5.81$ & $8-35$ \\
Auditory filtering & $22.01 \pm 5.17$ & $6-30$ \\
Low energy / weak & $25.09 \pm 5.37$ & $8-30$ \\
visual/auditory sensitivity & $18.9 \pm 4.41$ & $5-25$ \\
Total & $141.02 \pm 25.02$ & $65-184$ \\
\hline
\end{tabular}

Q2 Table 2: The number and the percentage of each result among all age groups for the 7 items of the SSP.

\begin{tabular}{lccc}
\hline & Typical performance & Probable difference & Definite difference \\
\hline Tactile sensitivity & $76(40 \%)$ & $39(20.5 \%)$ & $75(39.5 \%)$ \\
Taste and smell sensitivity & $75(39.47 \%)$ & $39(20.5 \%)$ & $76(40 \%)$ \\
Movement sensitivity & $76(40 \%)$ & $44(23.2 \%)$ & $70(36.8 \%)$ \\
Underresponsive.seek sensitivity & $57(30 \%)$ & $38(20 \%)$ & $95(50 \%)$ \\
Auditory filtering & $97(51.05 \%)$ & $45(23.7 \%)$ & $48(25.3 \%)$ \\
Low energy / weak & $102(53.68 \%)$ & $22(11.6 \%)$ & $66(34.7 \%)$ \\
visual/auditory sensitivity & $107(56.32 \%)$ & $49(25.8 \%)$ & $34(17.9 \%)$ \\
Total & $56(29.47 \%)$ & $38(20 \%)$ & $96(50.5 \%)$ \\
\hline
\end{tabular}

\section{Descriptive and analytical statistics:}

Table 3 shows the mean SD and the range among females in comparison to males' children (gender difference) for the 7 items of the SSP. The results show there was a significant difference in the Taste and smell sensitivity.

Table 4 shows the performance whether it is Typical performance, Probable difference or Definite difference in each of the 7 items of the SSP comparing females with males children

In males the Underresponsive/ seek sensitivity showed the highest percentage in 'definite difference' while Low energy /weak showed the highest percentage in 'typical performance'. As in females the taste/smell sensitivity showed the highest percentage in 'definite difference'. Regarding the highest percentage in "typical performance" was seen in the visual/auditory sensitivity among other items of the questionnaire.

The results statistically showed significant difference were noticed in the following items Taste and smell sensitivity $(p 0.030)$, Movement sensitivity $(p<0.001)$ and Underresponsive/seek sensitivity ( $p 0.014)$ as well as the total score $(p 0.017)$ between males and females' children. 
Table 3: The mean SD and the range among females in comparison to males' children (gender difference) for the 7 items of the SSP

\begin{tabular}{|c|c|c|c|c|c|c|}
\hline & \multicolumn{2}{|c|}{ Male } & \multicolumn{2}{|c|}{ Female } & \multicolumn{2}{|c|}{$\mathrm{t}$ test } \\
\hline & Mean & SD & Mean & SD & $\mathrm{t}$ & $p$ value \\
\hline Tactile sensitivity & 27.0 & 5.8 & 27.8 & 5.2 & -1.03 & 0.305 \\
\hline Taste and smell sensitivity & 13.5 & 4.8 & 12.0 & 4.5 & 2.18 & 0.030 \\
\hline Movement sensitivity & 11.5 & 3.1 & 11.4 & 2.9 & 0.18 & 0.860 \\
\hline Underresponsive.seek sensitivity & 22.8 & 5.7 & 24.1 & 5.9 & -1.62 & 0.107 \\
\hline Auditory filtering & 22.2 & 4.8 & 21.8 & 5.5 & 0.58 & 0.565 \\
\hline Low energy / weak & 25.0 & 4.8 & 25.3 & 6.0 & -0.39 & 0.699 \\
\hline visual/auditory sensitivity & 19.0 & 4.2 & 18.7 & 4.7 & 0.51 & 0.612 \\
\hline Total & 140.9 & 23.5 & 141.1 & 26.8 & -0.04 & 0.965 \\
\hline
\end{tabular}

Table 4: The performance whether it is Typical performance, Probable difference or Definite difference in each of the 7 items of the SSP comparing females with males' children.

\begin{tabular}{|c|c|c|c|c|c|c|c|}
\hline & & \multicolumn{2}{|c|}{ Male } & \multicolumn{2}{|c|}{ Female } & \multicolumn{2}{|c|}{ Chi square test } \\
\hline & & $\mathrm{N}$ & $\%$ & $\mathrm{~N}$ & $\%$ & $\chi^{2}$ & $p$ value \\
\hline \multirow{3}{*}{ Tactile sensitivity } & Typical performance & 36 & $34.6 \%$ & 40 & $46.5 \%$ & & \\
\hline & Probable difference & 20 & $19.2 \%$ & 19 & $22.1 \%$ & 4.45 & 0.108 \\
\hline & Definite difference & 48 & $46.2 \%$ & 27 & $31.4 \%$ & & \\
\hline \multirow{3}{*}{ Taste and smell sensitivity } & Typical performance & 43 & $41.3 \%$ & 32 & $37.2 \%$ & & \\
\hline & Probable difference & 25 & $24.0 \%$ & 14 & $16.3 \%$ & 3.25 & 0.197 \\
\hline & Definite difference & 36 & $34.6 \%$ & 40 & $46.5 \%$ & & \\
\hline \multirow{3}{*}{ Movement sensitivity } & Typical performance & 49 & $47.1 \%$ & 27 & $31.4 \%$ & & \\
\hline & Probable difference & 7 & $6.7 \%$ & 37 & $43.0 \%$ & 35.09 & $<0.001$ \\
\hline & Definite difference & 48 & $46.2 \%$ & 22 & $25.6 \%$ & & \\
\hline \multirow{3}{*}{ Underresponsive/seek sensitivity } & Typical performance & 25 & $24.0 \%$ & 32 & $37.2 \%$ & & \\
\hline & Probable difference & 17 & $16.3 \%$ & 21 & $24.4 \%$ & 8.50 & 0.014 \\
\hline & Definite difference & 62 & $59.6 \%$ & 33 & $38.4 \%$ & & \\
\hline \multirow{3}{*}{ Auditory filtering } & Typical performance & 46 & $44.2 \%$ & 51 & $59.3 \%$ & & \\
\hline & Probable difference & 27 & $26.0 \%$ & 18 & $20.9 \%$ & 4.48 & 0.107 \\
\hline & Definite difference & 31 & $29.8 \%$ & 17 & $19.8 \%$ & & \\
\hline \multirow{3}{*}{ Low energy / weak } & Typical performance & 55 & $52.9 \%$ & 47 & $54.7 \%$ & & \\
\hline & Probable difference & 13 & $12.5 \%$ & 9 & $10.5 \%$ & 0.20 & 0.906 \\
\hline & Definite difference & 36 & $34.6 \%$ & 30 & $34.9 \%$ & & \\
\hline \multirow{3}{*}{ Visual/auditory sensitivity } & Typical performance & 54 & $51.9 \%$ & 53 & $61.6 \%$ & & \\
\hline & Probable difference & 28 & $26.9 \%$ & 21 & $24.4 \%$ & 2.27 & 0.322 \\
\hline & Definite difference & 22 & $21.2 \%$ & 12 & $14.0 \%$ & & \\
\hline \multirow{3}{*}{ Total } & Typical performance & 33 & $31.7 \%$ & 23 & $26.7 \%$ & & \\
\hline & Probable difference & 13 & $12.5 \%$ & 25 & $29.1 \%$ & 8.11 & 0.017 \\
\hline & Definite difference & 58 & $55.8 \%$ & 38 & $44.2 \%$ & & \\
\hline
\end{tabular}

Correlation analysis (Pearson's and Spearman's correlation test): To assess the strength of association between two quantitative variables. The correlation coefficient denoted symbolically " $r$ and rs" defines the strength (magnitude) and direction (positive or negative) of the linear relationship between two variables shown in tables 5 (different Sensory abilities). In these results, the
Pearson correlation between the tactile sensitivity and the movement sensitivity is about 0.745 , which indicates that there is a large positive relationship between the 2 variables. And the Pearson correlation between the low energy/weak and the visual/auditory sensitivity is about 0.698 , which indicates that there is a moderate positive relationship between the 2 variables. 
Table 5: Correlation between hypersensitivity response to stimuli and the hypersensitivity response

\begin{tabular}{|c|c|c|c|c|c|c|c|}
\hline & & $\begin{array}{c}\text { Tactile } \\
\text { sensitivity }\end{array}$ & $\begin{array}{l}\text { Taste and } \\
\text { smell } \\
\text { sensitivity }\end{array}$ & $\begin{array}{l}\text { Movement } \\
\text { sensitivity }\end{array}$ & $\begin{array}{l}\text { Underresponsive/ } \\
\text { seek sensitivity }\end{array}$ & $\begin{array}{l}\text { Auditory } \\
\text { filtering }\end{array}$ & $\begin{array}{c}\text { Low } \\
\text { energy } \\
\text { weak }\end{array}$ \\
\hline \multirow{2}{*}{ Taste and smell sensitivity } & $\mathrm{r}$ & 0.459 & & & & & \\
\hline & $p$ value & $<0.001$ & & & & & \\
\hline \multirow{2}{*}{ Movement sensitivity } & $\mathrm{r}$ & 0.745 & 0.492 & & & & \\
\hline & $p$ value & $<0.001$ & $<0.001$ & & & & \\
\hline \multirow{2}{*}{$\begin{array}{l}\text { Underresponsive/ } \\
\text { seek sensitivity }\end{array}$} & $\mathrm{r}$ & 0.4 & 0.243 & 0.436 & & & \\
\hline & $p$ value & $<0.001$ & 0.001 & $<0.001$ & & & \\
\hline \multirow{2}{*}{ Auditory filtering } & $\mathrm{r}$ & 0.357 & 0.369 & 0.348 & 0.421 & & \\
\hline & $p$ value & $<0.001$ & $<0.001$ & $<0.001$ & $<0.001$ & & \\
\hline \multirow{2}{*}{ Low energy / weak } & $\mathrm{r}$ & 0.557 & 0.251 & 0.514 & 0.477 & 0.438 & \\
\hline & $p$ value & $<0.001$ & $<0.001$ & $<0.001$ & $<0.001$ & $<0.001$ & \\
\hline \multirow{2}{*}{ Visual/auditory sensitivity } & $\mathrm{r}$ & 0.669 & 0.448 & 0.612 & 0.469 & 0.49 & 0.698 \\
\hline & $p$ value & $<0.001$ & $<0.001$ & $<0.001$ & $<0.001$ & $<0.001$ & $<0.001$ \\
\hline
\end{tabular}

\section{DISCUSSION}

Sensory processing disorder have been known to physicians and parents who noticed that their children may have an unusual aversion to noise, light and or irritating touch. Some others may have fears from falling or seeks all kinds of movements. Others may suffer clumsiness and trouble in fine motor skills. These atypical behaviors like crashing into wall or people or screaming when their faces get dirty with food. Eating abnormally like eating mud or pieces of paper. All these behaviors may reflect a sensory processing disorder ${ }^{[16]}$

Difficulty in integrating information from senses have considered from physicians as a sign of autism spectrum disorder. This is because the majority of children and adults who were diagnosed as autism may have significant sensory problems ${ }^{[17]}$.

Some other studies ${ }^{[18]}$ and The Diagnostic and Statistical Manual of Mental Disorders ( $5^{\text {th }}$ ed.; DSM-5) found that many children with sensory problems are not on the spectrum. ${ }^{[19,20,21]}$ found that sensory problems may appear with attention deficit hyperactivity disorder and obsessivecompulsive disorder. Some other references recorded this disorder with developmental delayed children, like brain damage and learning disabilities ${ }^{[6,22,23]}$

This study declared that abnormality in tactile sensitivity and taste and smell sensitivity as well as seeking sensation is a common and the highest among normal toddlers using the short sensory profile (Table 1). This can be explained by children who become aggressive when they experience sensory overload. They develop panic response to everyday sensations that is usually normal to others. Not all kids respond to different sensations the same way. Some normal typically developing children have difficulty in the self-regulation mechanism responsible for the reaction or the response to tactile or movement sensitivity.

As some children experienced over or hypersensitivity and some others may experience hypo sensitivity. It was claimed that internal senses of body awareness (proprioception) and movement (vestibular) awareness when the brain showed conflicting signals as they have trouble sensing the amount of force needed to erase a paper and instead of that they rip it. This study proved that children with hyposensitivity are in constant motion, they crave fast, spinning and like jumping in the air while those with hypersensitivity feel panic from climbing stairs or playing balancing gym. Those avoiders or hypersensitive children and the seekers or hyposensitive children have poor body awareness and poor organization in the motor areas of the brain due to the distraction by the sensory problems (Table 2) ${ }^{[24,25,26]}$.

The significant findings of table 3 and 4 confirms the poor motor perception of some normal or typically developing children who showed some movement sensitivity difference as well as underresponsive seek sensitivity.

A correlative analysis (Table 5) was done to study the correlation between hypersensitivity response to stimuli and the hyposensitivity response. Positive correlation between the items of tactile sensitivity and taste and smell sensitivity may denote that the typically developing children who experienced one of the hypersensitivity disorders, may exhibit other disorders later in time. This positive correlation may help the physician or parents to look for other sensory disorders later in their child during his or her development.

The positive correlation between underresponsive seek sensitivity and low energy week sensitivity (Table 5) can 
be explained by the similar rule of poor body awareness and poor organization in the motor cortical areas of the brain. These items may be present in different percentage between the study subjects and larger number of subjects may be needed to demonstrate the changes among groups.

\section{CONCLUSION}

These findings showed the types of sensory processing impairments in typically developing children and the difference between boys and girls. Future studies are required on larger samples to clarify more the types of sensory impairment in typically developing children.

\section{CONFLICT OF INTEREST}

There are no conflicts of interest.

\section{REFERENCES}

1. Dunn W. (2014):Sensory Profile 2: User's Manual. USA: Pearson, Inc; (2014).

2. Dunn W.(2007): Supporting children to participate successfully in everyday life by using sensory processing knowledge. Infant Young Child 20(2):84101.10.1097/01.IYC.0000264477.05076.5d.

3. Yack E, Sutton S, Aquilla P.(2002): Building Bridges through Sensory Integration. Las Vegas, NV: Sensory Resources

4. Ayres J. Sensory Integration and Praxis Tests (SPIT)1989:. Los Angeles: Western Psychological Services.

5. Kuhaneck MH, Glennon TJ(2001): An Introduction to Autism and Pervasive Developmental Disorders. In: Kuhaneck MH. (eds) Autism, a Comprehensive Occupational Therapy Approach. The USA, The American Occupational Therapy Association. p1- 22.

6. Ahn, R. R., Miller, L. J., Milberger, S., and McIntosh, D. N. (2004): Prevalence of parents' perceptions of sensory processing disorders among kindergarten children. American Journal of Occupational Therapy, 58(3): 287-293

7. Brown T, Morrison IC, Stagnitti K. (2010): The convergent validity of two sensory processing scales used with school-age children: comparing the Sensory Profile and the Sensory Processing Measure. New Zeal J OccupTher 57(2):56-65.

8. Sensory Processing Disorder Foundation (2014)(n.d.): Sensory Processing Disorder Foundation | Research, Education, and Advocacy. https://www.spdfoundation. net/index.html.
9. Dunn, W. (1999): Short Sensory Profile. Psychological Corporation: San Antonio, TX.

10. Vanzetta, I., and Grinvald, A. (2008): Coupling Between Neuronal Activity and Microcirculation: Implications for Functional Brain Imaging. HFSP Journal, 2(2): 79-98.

11. Spitzer, S. and Roley, S.S. (2001): Sensory Integration Revisited. In: Roley SS, Blanche EI, Schaaf RC. (eds) Understanding the Nature of Sensory Integration with Diverse Population. Therapy Skill Builders: TX.

12. Parham, D. and Mailloux, Z. (2005): Sensory Integration. In: Case-Smith J. (ed) Occupational Therapy for Children, Elsevier Mosby. p356- 409.

13. Dunn W. (2001): The sensations of everyday life: empirical, theoretical, and pragmatic considerations. Am J OccupTher 55(6):608-20.10.5014/ajot.55.6.608

14. Dunn W and Brown C.(1997): Factor analysis on the Sensory Profile from a national sample of children without disabilities. Am J OccupTher 51(7):490-5; discussion 6-9.

15. McIntosh, D. N., Miller, L. J., andShyu, V. (1999). Development and validation of the Short Sensory Profile. In W. Dunn(Ed.), Sensory Profile manual (pp. 59-73). San Antonio, TX: Psychological Corporation.

16. Ben- Sasson, A.; Carter, A.S.; Briggs- Gowan,M. (2009): Sensory overresponsivity in Elemntary school: Prevalence and Social-emotional correlates. Journal of Abnormal child psychology 37 950: 705-716.

17. Dawes, P., and Bishop, D. (2009). Auditory processing disorder in relation to developmental disorders of language, communication and attention: a review and critique. International Journal of Language and Communication Disorders, 44(4), 440-465.

18. Chang, Y. S., Gratiot, M., Owen, J. P., BrandesAitken, A., Desai, S. S., Hill, S. S., ... and Mukherjee, P. (2016). White matter microstructure is associated with auditory and tactile processing in children with and without sensory processing disorder. Frontiers in neuroanatomy, 9, 169.

19. Shimizu, V. T., Bueno, O. F., and Miranda, M. C. (2014): Sensory Processing Abilities of Children with ADHD. Brazilian Journal of Physical Therapy, 18(4): 343-352.

20. Pfeiffer, B., Daly, B. P., Nicholls, E. G., and Gullo, D. F. (2015): Assessing Sensory Processing Problems in Children with and without Attention Deficit Hyperactivity Disorder. Physical and Occupational Therapy in Pediatrics, 35(1): 1-12.

21. Torres, A. R., Prince, M. J., Bebbington, P. E., Bhugra, 
D., Brugha, T. S., Farrell, M., and Singleton, N. (2006): Obsessive-Compulsive Disorder: Prevalence, Comorbidity, Impact, and Help-Seeking in The British National Psychiatric Morbidity Survey of 2000. American Journal of Psychiatry, 163(11): 1978-1985.

22. Cheung, P. P., and Siu, A. M. (2009): A Comparison of Patterns of Sensory Processing in Children with and without Developmental Disabilities. Research in Developmental Disabilities, 30(6): 1468-1480.

23. Engel-Yeger, B., Hardal-Nasser, R., and Gal, E. (2011): Sensory Processing Dysfunctions as Expressed Among Children with Different Severities of Intellectual Developmental Disabilities. Research in Developmental Disabilities, 32(5): 1770-1775.

24. Miller L J, Schoen SA, James K, Schaaf RC (2007) Lessons learned: a pilot study on occupational therapy effectiveness for children with sensory modulation disorder. Am J OccupTher. Mar-Apr; 61(2):161-9.

25. Miller L J, Nielsen DM, Schoen SA (2012):Attention deficit hyperactivity disorder and sensory modulation disorder: a comparison of behavior and physiology. Res Dev Disabil. 2 May-Jun; 33(3):804-18.

26. Schaaf R C, Lane AE. Toward a best-practice protocol for assessment of sensory features in ASD. J Autism Dev Disord (2015) 45(5):1380-95.10.1007/s10803014-2299-z. 